\section{Lyme law: targeting best practices}

In her defence of the alternative views on Lyme disease diagnosis behind Bill C-442, Zubek ${ }^{1}$ is certainly right to focus on the patients in her response to CMAJ's article on Lyme disease. ${ }^{2}$ Many people who are under the impression that they have Lyme disease based on alternative approaches to diagnosis are disabled and in need of an open-minded approach to care. What will not help is a flawed diagnosis.

Lyme disease is making ecological inroads in Nova Scotia, southern Ontario and elsewhere, but Zubek writes from British Columbia. From her letter, one might think Lyme disease is everywhere, regularly missed, and that all we have to do to sort things out is employ alternative testing from specialty laboratories in the United States or diagnose Lyme disease based on any array of nonspecific findings.

In actual fact, ticks of all stages are under regular surveillance in BC using methods capable of detecting all strains of Borrelia with sensitive polymerase chain reaction methodology. ${ }^{3}$ As in the 1990s, only 1 in 200 Ixodes ticks in the province carry the pathogen, it is the standard North American strain, and this prevalence remains 50 - to 100 -fold less than in highly endemic areas in the US Northeast.

Henry's observations ${ }^{4}$ that family physicians do treat enlarging circular rashes as Lyme disease means that we have considerable vigilance on the front line, but given the broad array of dermatologic entities that may cause such a rash, also implies that an appropriate degree of overtreatment is going on, not that every case is Lyme disease. In the area of testing, a definitive study has shown that "specialty labs" not only failed to perform better than reference laboratories in finding Borrelia infection, but also, outrageously, labelled more than $50 \%$ of healthy controls as having it. ${ }^{5,6}$

The term junk science applies when one holds onto a nontestable hypothe-

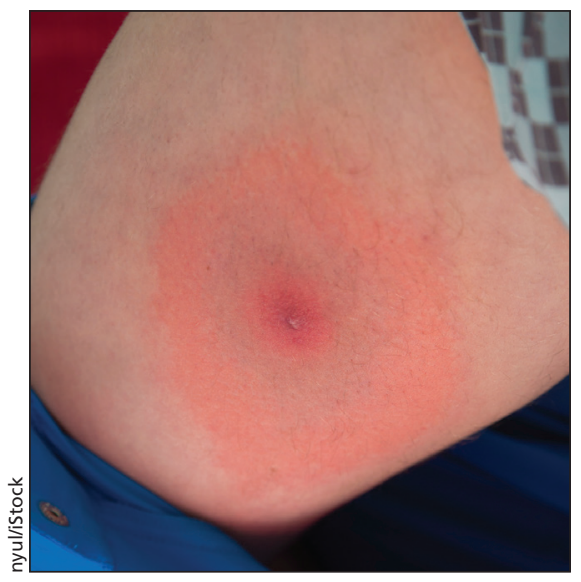

sis, fails to test it and expects one's critics to do so. In 2015, we should not state that a clinical diagnosis based, not on specific Borrelia-associated pathology, but on any array of nonspecific symptoms, is the best we can do.

I welcome Zubek's advocacy for a stronger model of patient care for people with difficult chronic symptoms, but note that flawed and premature conclusions about etiology hurt the very patients we are trying to help.

\section{David M. Patrick MD}

School of Population and Public Health, University of British Columbia, Vancouver, BC

\section{References}

1. Zubek E. The Lyme law [letter]. CMAJ 2015;187: 520-1.

2. Brown C. Lyme law uses "junk science" says expert. CMAJ 2014;186:1354

3. Morshed M, Lee K, Man S, et al. Surveillance for Borrelia burgdorferi in Ixodes ticks and mice in British Columbia [lecture]. ID Week 2014; 2014 Oct. 8-12; Philadelphia. Available: https://idsa.confex .com/idsa/2014/webprogram/Paper46098.htm

4. Henry B. Lyme disease: Knowledge, beliefs, and practices of physicians in a low-endemic area. Can Fam Physician 2012;58:e289-95

5. Fallon BA, Pavlicova M, Coffino SW, et al. A comparison of lyme disease serologic test results from 4 laboratories in patients with persistent symptomsafter antibiotic treatment. Clin Infect Dis 2014; 59:1705-10.

6. Dattwyler RJ, Arnaboldi PM. Comparison of lyme disease serologic assays andlyme specialty laboratories. Clin Infect Dis 2014;59:1711-3.

\section{CMAJ 2015. DOI:10.1503/cmaj.1150054}

\section{Carter v. Canada}

We applaud CMAJ's efforts at advancing the discussion on physician-assisted suicide; however, we take exception to several of the points presented in Downey's commentary. ${ }^{1}$

First, this issue is not about physicians balking at oversight, it's about physicians being asked to do something contrary to their current practice. Let's not turn this into something more convoluted.

Second, Downey states that much may be learned from the experience of others, including palliative care physicians. ${ }^{1}$ Is the suggestion that palliative care physicians represent the de facto group to advance physician-assisted suicide? Let's be clear that palliative care physicians have stated that they do not want to be associated with physician-assisted suicide. ${ }^{2}$ Our focus is to relieve suffering, not to terminate life. Many of our patients already view the palliative care team as the grim reaper service. Adding a clear association with physician-assisted suicide will only exacerbate this.

Third, Downey states that both new and experienced physicians will need to learn how to deliver assisted dying. The number of patients requesting assisted suicide is very small. Do we want to spend considerable time and resources teaching medical students and experienced physicians an "intervention" that the vast majority will never carry out? A group of providers who want to do this will need to be identified and receive appropriate training and regulation.

What is truly needed is better access to palliative care training for both trainees and experienced physicians. Palliative care is given only minimal consideration in current medical school curricula, and yet, the vast majority of physicians will at some point be responsible for the care of patients near the end of life. Let's put our resources where we can make a meaningful impact for the vast majority of our patients.

\section{Michael Slawnych MD PhD, Leonie Herx MD PhD, Jessica Simon MD, Srini Chary MD}

Division of Cardiology, Libin Cardiovascular Institute (Slawnych); Departments of Paediatrics (Herx) and Oncology (Simon, Chary), University of Calgary, Calgary, Alta. 